\title{
Rate of Reusable and Recyclable Waste in Construction
}

\author{
Vivian W.Y. Tam ${ }^{*}, 1$ \\ School of Engineering, University of Western Sydney, Penrith South DC, NSW 1797, Australia
}

\begin{abstract}
Construction solid waste has caused serious environmental problems. Reuse, recycling and reduction of construction materials have been advocated for many years, and various methods have been investigated. However, the effectiveness of its applications seems limited. This paper examines rates of reusable and recyclable waste for six major types of building materials: plastic, paper, timber, metal, glass and concrete. The rates of reusable and recyclable waste define as ratios of actual reusable and recyclable material over total construction waste. Five case studies are conducted in Hong Kong for the investigation. It is found that "metal" has the highest rate of reusable and recyclable waste and "plastic" has the lowest rate. This examination leads to the identification of the major barriers on reuse and recycling of construction materials in the local construction industry. Recommendations to improve the reusable and recyclable rates are also discussed.
\end{abstract}

Keywords: Construction waste, rate of reusable and recyclable waste, waste management, Hong Kong.

\section{INTRODUCTION}

Construction waste has caused serious environmental problems in many large cities [1,2]. Enormous amounts of infrastructure and building work have been built, so numbers of demolished structures are also increasing in construction work [3]. As increasing demands of dumping areas for never-ended demolished waste are thrown away, there is a shortage of landfills. Therefore, reducing waste generation becomes a pressing issue around the world.

There is a responsibility to ensure that construction activities and products are consistent with environmental policies and good environmental practices through waste reduction [4]. The best way to deal with material waste is not to create it in the first place [5-7]. One of the major hindrances to waste minimization on a construction site is the difficulty in establishing a methodology and using this methodology to benchmark future construction projects. For overcoming this shortage, a waste minimization system called Site Methodology to Audit Reduced Target Waste (SMARTWaste) introduced by McGrath for auditing, reducing and targeting waste arising on construction sites for improving material recovery for reusing and reducing waste arising on future sites [8]. In applying the systems, audited waste arising is used as a benchmark. A theory of waste behaviour for construction industry to investigate attitudinal forces that shape behaviour at the operational level has been perceived by Teo and Loosemore [2], in which they recommended to help managers improving operatives' attitudes towards waste and help them find economic incitements.

Although recycling and sustainable use of resources are increasingly promoted in construction activities, and efforts have particularly been made in recycling materials such as

*Address correspondence to this author at the School of Engineering, University of Western Sydney, Penrith South DC, NSW 1797, Australia; Tel: (61) 2-4736-0105; Fax: (61) 2-4736-0833;

E-mail: vivianwytam@gmail.com concrete, mortar, steel and soil, there was limited studies showing how effective these implementation measures are [9]. This paper examines rates of reusable and recyclable waste for six major types of construction materials: plastic, paper, timber, metal, glass and concrete. The data used for analysis is collected from a practical survey with five local case studies. The examination can illustrate which types of materials are effectively recycled and reused in the construction practices. On the other hand, hindrances on reusing and recycling different types of materials are to be identified. Consequently the survey findings can lead developing methods to improve the rates of reusable and recyclable materials across various types of construction materials and to find economic incitements.

\section{WASTE PROBLEMS IN CONSTRUCTION}

Waste defines as any material by-product of human and industrial activity that has no residual value [10]. From the statistic of Environmental Protection Department [4], about $38 \%$ of total waste is generated from construction and demolition activities, which is about 6,408 tonnes of waste per annum are produced from construction activities.

From the huge amount of construction waste, it is found that quantities of ferrous metals are represented to about $45.5 \%$ with about 803,190 tonnes of the total recyclable materials and about $37.7 \%$ with about 665,539 tonnes from wood and paper. Furthermore, non-ferrous metals have the highest value of recyclable volume, in which it valued as one million dollars. For the total recyclable materials, ferrous and non-ferrous metal, wood and paper are incorporated to about $87.1 \%$ of the total quantity of exported recyclable materials and about $87.2 \%$ of the total values of materials. Therefore, it is necessary to reduce waste generated of these three categories of materials for effectively and efficiently reducing waste problems.

\section{WASTE MINIMIZATION TECHNIQUES}

While serious pollution generated from construction activities, a comprehensive construction waste management 
is urgently needed on every construction site. It is of great importance to structure ways for minimizing waste generation is seen as the most favorable solution to waste problems of any kind. Indeed, it should be made compulsory that every construction company should enact construction waste management plan tailored to its particular mode of business so that every personnel from the management to the operational level can head for the same goal of construction waste management.

Economic and environmental benefits to be gained from waste minimization are important [11], since it will benefit both the environment and construction firms in terms of cost reduction. The economic benefits of waste minimization include possibilities of selling specific waste materials and removal from sites of other waste at no charge or reduced cost, with a subsequent reduction in materials going to landfill [7]. Therefore, it can increase contractors' competitiveness through lower production cost and a better public image. However, very few contractors have spent efforts in considering the environment and developing methods for minimizing building waste [12]. Because contractors rank timing as their top priority for their projects, their effort is always focused on completing projects in the shortest time, rather than the environment $[13,14]$. Their account books cannot reveal potential savings resulted from reduction in construction waste. Managing building material waste can in fact achieve high construction productivity, save in time and improvement in safety $[6,15,16]$ while extra waste takes extra time and resources for disposal that may slow down construction progress.

Waste minimization is any techniques, process or activities which avoids, eliminates or reduces waste at its source or allows reuse or recycling waste for benign purposes [17]. There are many possibilities for disposing waste from construction and demolition activities, from recycling to incineration and landfilling. Prior to considering various options that could be utilized, a hierarchy of disposal options needs to be captured into six levels, from low to high impacts, namely, reduce, reuse, recycle, compost, incinerate and landfill [18]. Three main waste minimization strategies identified are reusing, recycling and reducing construction materials, collectively called ' 3 Rs' and these are presented in the order of preference, representing a hierarchy of environmental benefits and potentials for economic saving [19].

\section{RESEARCH METHODOLOGY}

Reusing and recycling waste can reduce waste material volumes to be disposed of and discharged into the environment. Direct reuse of waste materials in its original or slightly altered involves reprocessing of used materials into new materials. Reusing and recycling construction waste is the best option to be chosen where reduction is not possible. Although contractual provisions are found to be effective in clarifying obligations and responsibilities, such means may not be properly applied to compulsorily require construction waste management to be established on every site as technical and financial problems are to be solved. Seven determining factors in the success for recycling construction and demolition waste include [18]: i) good site and site location; ii) proper equipment; iii) experience in construction and demolition recycling operations; iv) trained supervisors and employees; v) knowledge of secondary material markets; vi) business and financial capacities; and vii) knowledge of environmental regulations.

To investigate actual practices on reusing and recycling construction materials on site activities, five case studies are under investigation on the rates of reusable and recyclable waste in construction. All case studies are private housing projects and the data collected are at the construction stage. Six most common construction materials including: i) plastic; ii) paper; iii) timber; iv) metal; v) glass; and vi) concrete, are studied in this paper. The rates of reusable and recyclable waste define as ratios of actual reusable and recyclable materials over total construction waste, as formulated in Equation (1):

$$
\begin{aligned}
& \text { Rate of Reusable Actual Reusable and } \\
& \text { and Recyclable } \frac{\text { Recyclable Material }}{\text { Total Construction Equation (1) }} \\
& \text { Waste }=\quad \text { Waste }
\end{aligned}
$$

The rates of reusable and recyclable waste indicate that practice of reusing and recycling construction materials on the measured case studies; 1 indicates that there is fully reusable and recyclable all construction materials; while 0 indicates that it turns all construction materials into waste for disposal. The value for rate of reusable and recyclable waste is continuous based on the calculations from Equation (1).

Individual structured interviews are arranged with each case study, including project managers, quantity surveyors, site foremen and on-site workers. The interviews with all project participants for the same case study are arranged, the involvement with all participants can ensure all project participants understanding the requirements of the project and cross-checking of data provided is accurate Three faceto-face interviews are arranged for each case study, which include the first interview on explaining the project details and data required, the second interview on consolidating data from different project participants and the third interview on commenting the data provided and made final corrections. The interviews are intended for gathering further comments, elaboration and interpretation on the results obtained from the survey.

\section{RESULTS AND DISCUSSIONS}

Table 1 shows the survey results on the rates of reusable and recyclable waste for six types of construction materials for the five case studies. "Plastic" measured low rates of reusable and recyclable waste for the case studies. It is measured 0 on the rates for Case studies 1 and 3 from the survey results. An interviewed project manager on Case study 1 explained that plastic is hard to reuse and recycle on site. The existing technologies are not enough to effectively and efficiently recycle plastic. The interviewed site foreman also explained that quantities generated for plastic waste is not high, which will reduce their motivation to find ways for reusing and recycling plastic.

From the survey, it is found that "paper" has relatively high rates of reusable and recyclable waste of about 0.70 to 0.95 from the survey results. This is indicated that construction organizations have high environmental awareness on reusing and recycling paper. From the 
Table 1. Rates of Reusable and Recyclable Waste on Construction Materials

\begin{tabular}{|c|c|c|c|}
\hline Case Studies & Total Waste (Tonne) & Actual Reusable and Recyclable Waste (Tonne) & Rate of Reusable and Recyclable Waste \\
\hline \multicolumn{4}{|l|}{ Case Study 1} \\
\hline Plastic & 0.3 & 0 & 0 \\
\hline Paper & 1 & 0.7 & 0.70 \\
\hline Timber & 30 & 10 & 0.33 \\
\hline Metal & 200 & 200 & 1 \\
\hline Glass & 1 & 0.4 & 0.40 \\
\hline Concrete & 100 & 40 & 0.40 \\
\hline \multicolumn{4}{|l|}{ Case Study 2} \\
\hline Plastic & 0.5 & 0.2 & 0.40 \\
\hline Paper & 1 & 0.9 & 0.90 \\
\hline Timber & 20 & 10 & 0.50 \\
\hline Metal & 100 & 100 & 1 \\
\hline Glass & 1.5 & 0.5 & 0.33 \\
\hline Concrete & 20 & 5 & 0.25 \\
\hline \multicolumn{4}{|l|}{ Case Study 3} \\
\hline Plastic & 0.7 & 0 & 0 \\
\hline Paper & 1 & 0.8 & 0.80 \\
\hline Timber & 5 & 4 & 0.80 \\
\hline Metal & 70 & 70 & 1 \\
\hline Glass & 10 & 4 & 0.40 \\
\hline Concrete & 250 & 200 & 0.80 \\
\hline \multicolumn{4}{|l|}{ Case Study 4} \\
\hline Plastic & 1 & 0.2 & 0.2 \\
\hline Paper & 10 & 8 & 0.80 \\
\hline Timber & 200 & 150 & 0.75 \\
\hline Metal & 500 & 400 & 0.80 \\
\hline Glass & 200 & 50 & 0.25 \\
\hline Concrete & 300 & 270 & 0.90 \\
\hline \multicolumn{4}{|l|}{ Case Study 5} \\
\hline Plastic & 1 & 0.1 & 0.1 \\
\hline Paper & 1 & 0.95 & 0.95 \\
\hline Timber & 150 & 85 & 0.56 \\
\hline Metal & 300 & 240 & 0.80 \\
\hline Glass & 100 & 1 & 0.10 \\
\hline Concrete & 400 & 20 & 0.05 \\
\hline
\end{tabular}

interview discussions with the construction practitioners, the interviewees explained that paper can easily be reused and recycled. Cardboard and paper comprise about 37\% of construction and demolition waste by volume [4]. Recyclers normally reprocess into new paper products. Another interviewee noted that it is encouraged to use two-side copied paper and using Internet downloading for reducing paper consumption. Furthermore, packaging materials can be collected and reused by the material suppliers.

"Timber" has relatively variant rates of reusable and recyclable waste collected from the survey. Cases studies 3 and 4 measured the rates of about 0.80 and 0.75 respectively from the survey; however, as low as 0.33 is measured on the rate for Case study 1 . The low rate of reusable and recyclable waste may come from low environmental awareness on site. 
From the interview discussions with the project managers on the Cases studies 3 and 4, they highlighted that it is easy to reuse and recycle used timber for other purposes on site, such as temporary work. Furthermore, timber waste can be chopped and sold as landscaping mulch. Waste timber can also be reused in the form of interior fixture and furniture and act as organic-bonded or cement-bonded boards for roofing felt, fiberboard and animal bedding. Timber formwork is the most usual form for formwork, however, it is encouraged and recommended to use other durable materials, such as steel or aluminum, in substitute the nonenvironment-friendly materials, timber.

The rates of reusable and recyclable waste on "metal" have relatively high reusable and recyclable rates of 1.00 for Cases studies 1, 2 and 3 from the survey. The high recycling rates obtained can be explained by high profit making of metal in the market. However, the interviewees highlighted that it is hard to reuse short pieces of metal on site. At site, not much metal is taken to waste because it is by far the most profitable material as demands for such waste have long been well established. The applications of metal had been well established on site conditions.

The rates of reusable and recyclable waste for "glass" are between 0.10 and 0.40 for the case studies from the survey. From the interview discussions, the on-site workers explained that glass waste is mainly generated from cutting to the required dimensions and damages during transportation. Therefore, the reusability and recyclability of glass waste are not high. As if glass is damaged, it is hard to be reused or recycled on site. One of the interviewees noted

Table 2. Typical Measures for Reusing, Recycling and Reducing Construction Materials

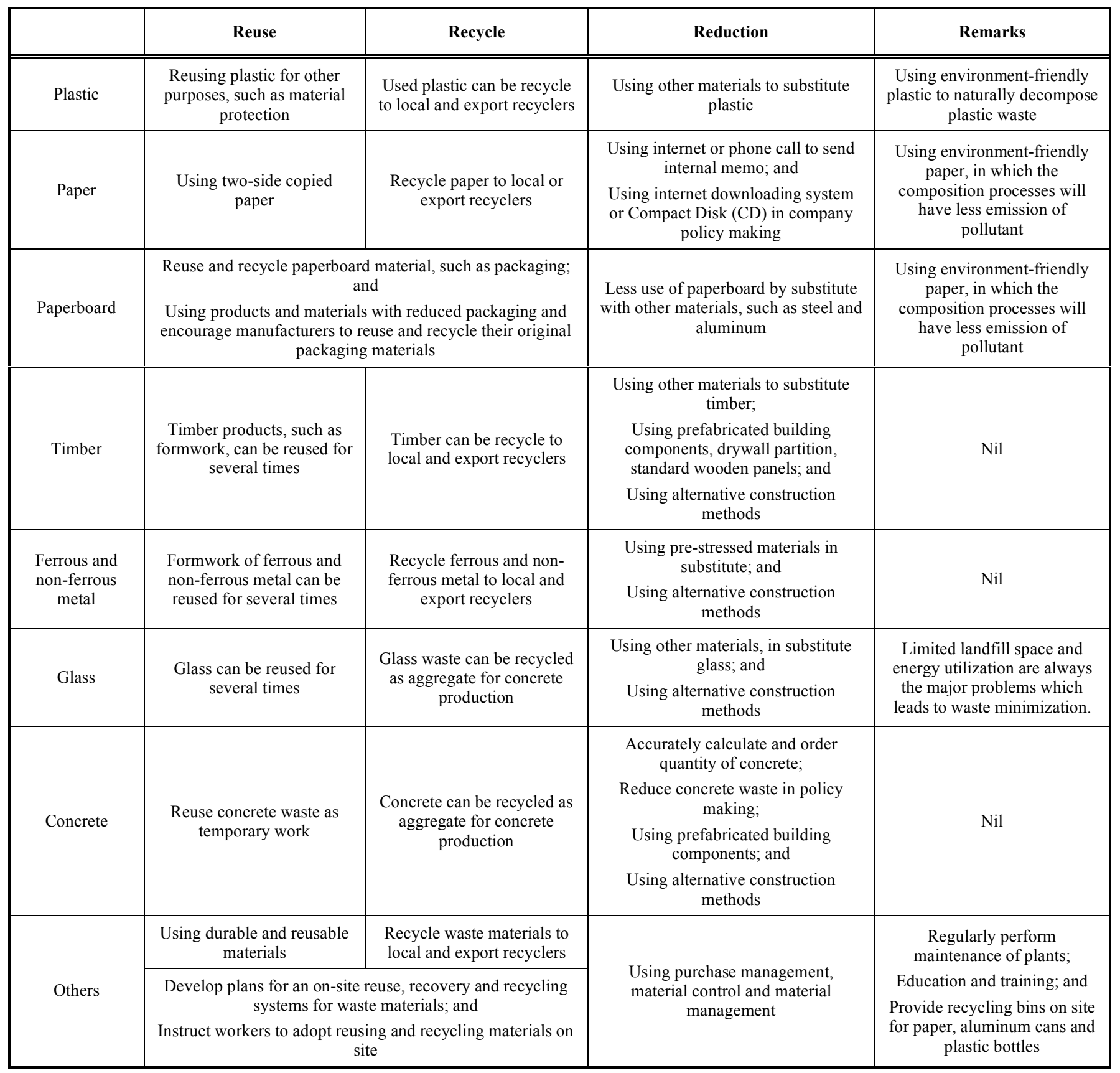


that it is suggested to reduce glass consumption on site. Another interviewee highlighted that there are on-going researches examining the use of glass waste as aggregate for concrete production. This can significantly reduce landfill consumption for glass waste. Limited landfill space is always the major problem and bring the attention for waste recycling.

"Concrete" has measured with the wide range on the rates from 0.05 to 0.90 for the case studied from the survey. The interviewed quantity surveyors explained that projects cannot order concrete as the same calculation from bills of quantity without considering wastage. On-site practices are always ordering about $5-10 \%$ extra concrete to the construction site. One of the main problems is that organizations cannot afford to have not enough concrete for on-site concreting activities; otherwise, whole building structures will be changed. Another interviewee suggested that the use of on-site mobile crushers can help reducing concrete waste by crushing it as recycled aggregate for concrete production. However, based on the limited space on site environment, the mobile crusher is not commonly using it in the construction industry. The best way to reduce concrete waste is to use prefabrication instead of in-situ concreting, as suggested by an interviewee.

\section{RECOMMENDATIONS}

To reduce on-site waste generation, coordination among all those involved in the design and construction processes are essential and meetings should occur on a regular basis to address waste issues. Waste minimization can be easier achieved on the normal practices of building work through "3Rs", such as reducing concrete by using prefabricated building components; reusing steel formwork as its maximum applications; and recycling steel for generating income [19]. Although promotion of reuse, recycle and reduction is suggested in construction for several years, satisfactory environmental awareness seem cannot be achieved in different layers of management support. The main problem of inefficient and ineffective practices of reuse, recycle and reduction of construction waste is lack of understanding in treatment for construction waste. Based on the discussions with construction practitioners, several measures of reusing, recycling and reducing construction materials are suggested in Table 2 .

\section{CONCLUSION}

As environmental protection has been pressing hard around the world, high energy utilization and pollution generation from construction activities seems cannot be controlled. Reusing, recycling and reducing construction materials have been encouraged and suggested for the practices in construction activities. This paper investigated the rates of reusable and recyclable waste for plastic, paper, timber, metal, glass and concrete from five case studies. It was found that "metal" has the highest rate as the high profit making on recycling while "plastic" has the lowest rates. Recommendations on reusing, recycling and reducing construction materials were also discussed.

\section{REFERENCE}

[1] Z. Chen, H. Li and T. C. Wong, "An application of bar-code system for reducing construction wastes", Automation in Construction, vol. 11, no. 5, pp. 521-533, 2002.

[2] M. M. M. Teo and M. Loosemore, "A theory of waste bahaviour in the construction industry", Journal of Construction Management and Economics, vol. 19, no. 7, pp. 741-751, 2001.

[3] H. Kawano, "The state of reuse of demolished concrete in Japan", Integrated design and environmental issues in concrete technology : proceedings of the International Workshop 'Rational Design of Concrete Structures under Severe Conditions' Hakodate, Japan, pp. 243-249, 1995.

[4] Environmental Protection Department (2005), Environmental protection, http://www.info.gov.hk/epd, Environmental Protection Department, Hong Kong Special Adminstrative Region, China.

[5] Environmental Protection Department, Hong Kong Environment 2001. Hong Kong Government, 2001.

[6] R. M. Gavilan and L. E. Bernold, "Source evaluation of solid waste in building construction", Journal of Construction Engineering and Management, vol. 120, no. 3, pp. 536-555, 1994.

[7] K. Snook, A. Turner and R. Ridout, Recycling waste from the construction site. England: Chartered Institute of Building, 1995.

[8] C. McGrath, "Waste minimization in practice", Resources, Conservation and Recycling, vol. 32 pp. 227-238, 2001.

[9] V. W. Y. Tam and C. M. Tam, "Evaluations of existing waste recycling methods: A Hong Kong study", Building and Environment, vol. 41, no. 12, pp. 1649-1660, 2006.

[10] A. Serpell and L. F. Alarcon, "Construction process improvement methodology for construction projects", International Journal of Project Management, vol. 16, no. 4, pp. 215-221, 1998.

[11] P. Guthrie, A. C. Woolveridge and V. S. Patel, Waste minimisation in construction: site guide. London: Construction Industry Research and Information Association, 1999.

[12] A. L. P. Lam, A study of the development of environmental management in Hong Kong construction industry, The Hong Kong Polytechnic University, 1997.

[13] C. S. Poon, T. W. Yu and L. H. Ng, A guide for managing and minimizing building and demolition waste. The Hong Kong Polytechnic University, 2001.

[14] C. S. Poon, T. W. Yu and L. H. Ng, "On-site sorting of construction and demolition waste in Hong Kong", Resources, Conservation and Recycling vol. 32 pp. 157-172, 2001.

[15] A. P. C. Chan and T. Y. F. Ma, "Materials wastage on commerical projects - contractor's view", Proceedings of the Sixth East AsiaPacific Conference on Structure Engineering and Construction, Taipei, Taiwan, pp. 1059-1064, 1998.

[16] E. R. Skoyles and J. R. Skoyles, Waste prevention on site. London: Mitchell, 1987.

[17] Sustainable construction, Proceedings of the first international conference of CIB TG 16 Ganiesville, Fla Centre for Construction and Environment, 1994.

[18] C. L. Peng, D. E. Scorpio and C. J. Kibert, "Strategies for successful construction and demolition waste recycling operations", Journal of Construction Management and Economics, vol. 15, no. 1, pp. 49-58, 1997.

[19] L. Y. Shen and W. Y. V. Tam, "Implementing of environmental management in the Hong Kong construction industry", International Journal of Project Management, vol. 20, no. 7, pp. 535-543, 2002. 